\title{
Questão Ambiental e Gênero: Algumas aproximações ao longo do tempo e do espaço
}

\author{
Environmental Issue and Gender: Some approaches over time and space
}

\author{
Juliana Freitas de Cerqueira Guedes \\ Centro Universitário Jorge Amado \\ juliguedes@yahoo.com.br
}

Ihering Guedes Alcoforado

Universidade Federal da Bahia

ihering@ufba.br

\section{Resumo}

O objetivo deste trabalho é mostrar a contribuição da análise de gênero no campo das políticas ambientais, em especial, às condições de possibilidades analíticas abertas pelo conceito de Revoluções Ecológicas da filósofa da ciência e ecofeminista norte-americana, Merchant (1983, 1989, 1992). Associamos o tempo às três Revoluções Ecológicas: Colonial, Capitalista e Global e o espaço por meio da mudança de escala ao longo das Revoluções Ecológicas.

Palavras-chave: Gênero; meio ambiente; revoluções ecológicas.

\begin{abstract}
The objective of this work is to show the contribution of gender analysis in the field of environmental policies, in particular the conditions of analytical possibilities opened by the concept of Ecological Revolutions of ecofeminist philosopher of science and American, Merchant (1983, 1989, 1992). We associate time to three Ecological Revolutions: Colonial, Capitalist and Global and space through the change of scale along the Ecological Revolutions.
\end{abstract}

Keywords: Gender; environment; ecological revolutions. 


\section{Introdução}

O presente trabalho apresenta a contribuição da filósofa da ciência e ecofeminista norte-americana Merchant (1983, 1989, 1992) como desveladora do papel central do gênero na estruturação dos metasdiscurso socioambientais dedicados à reflexão dos processos de mudanças na relação do homem com a natureza ao longo do tempo e do espaço. O tempo é representando pelas três Revoluções Ecológicas: Colonial, Capitalista e Global e o espaço pelas distintas relações de gênero na propriedade privada ao longo das Revoluções Ecológicas. O objetivo é chamar atenção para as possibilidades de tal análise no campo das políticas ambientais.

Inicialmente introduzimos a compreensão de Merchant (1983 e 1989) da ordem orgânica cuja concepção é de que todas as partes da natureza são mutuamente interdependentes, com temporalidade circular e regime de propriedade comum que a levou a identificar 'afinidades eletivas' com gênero feminino; ao mesmo tempo em que a ordem mecânica adota uma temporalidade linear e regime de propriedade privada, adotando a ideia de que o homem está acima da natureza no que vislumbra 'afinidades eletivas' com o gênero masculino. Logo em seguida, mostrar-se-á como ela argumenta a associação da ordem orgânica à Revolução Ecológica Colonial e ao gênero feminino e a ordem mecânica à Revolução Ecológica Capitalista e ao gênero masculino. Fechando essa parte com a introdução do seu conceito de Revolução Ecológica Global.

Mostrar-se-á que a ascensão de uma consciência analítica e quantitativa foi o traço da Revolução Ecológica Capitalista, a qual representou a hegemonia da ordem mecânica em que ordem e poder constituem um controle acima da natureza. Estes valores são compatíveis com os rumos do capitalismo comercial em que a sociedade é fundamentada na competição e não no compartilhamento. $\mathrm{E}$, que, na maioria das vezes, este tipo de atitude acarreta consequências desastrosas para a humanidade na forma de poluição e degradação dos recursos, não se excluindo o risco de desastres.

Versaremos que a Revolução Ecológica Global de Merchant (1989) poderá reconstruir as relações de gênero entre mulheres e homens e entre humanos e a natureza. Neste âmbito, chamamos atenção que o ecodesenvolvimento e o ecofeminismo de Merchant (1989 e 1992) podem oferecer um ponto de partida para a discussão de uma nova ética para as relações entre o ser humano e a natureza articulada a partir de um deslocamento da ética da convicção antropocêntrica para uma ética da responsabilidade ecocêntrica. Isto porque, pode-se considerar que o pensamento mecânico articula-se a partir de uma ética antropocêntrica em que o homem submete a natureza a seus princípios, a exemplo da maximização do seu próprio interesse.

Argumentaremos que da Revolução em tela podemos extrair alguns pontos de interesse aos formuladores da política ambiental no século XXI, explorando as implicações dos deslocamentos dos fundamentos éticos da política ambiental de uma ética antropocêntrica voltada para uma política da vizinhança, para uma ética ecocêntrica focada numa política da sobrevivência. De forma a dar conta de uma política realidade que passa a considerar como objeto os novos impactos ambientais que, de impactos locais e reversíveis, começam a se revelar impactos globais e irreversíveis.

Por fim, chamamos atenção que já não é mais pertinente operar com o paradigma da 'política da convivência' fundado numa ética antropocêntrica que se expressa em um framework fundado numa representação mecanicista da natureza. E argumentamos a pertinência de diante dos novos impactos globais e irreversíveis, que traz consequências inesperadas, recorrermos a um framework com base no princípio da precaução e da responsabilidade, o que sugerimos ser operacionalizada por meio da Revolução Ecológica Global.

\section{Organicismo, Mecanicismo e Revoluções Ecológicas}

O primeiro passo na representação orgânica da natureza surgiu na Renascença e suas ideias tiveram raízes nos conceitos gregos do cosmo como um organismo inteligente. Conceitos estes que foram revividos, modificados e assimilados na consciência dos séculos XV e XVI. Três raízes tradicionais se tornaram a base para uma posterior forma sincrética do pensamento orgânico: Platonismo, Aristotelianismo e Estoicismo (MERCHANT, 1983).

O ponto comum nestas três raízes tradicionais é que todas as partes do cosmo estão conectadas e interrelacionadas em uma unidade de vida. Ou seja, todas as partes da natureza são mutuamente interdependentes e cada uma reflete mudanças no resto do cosmo, que é a totalidade de todas as coisas do Universo ordenado, desde as estrelas até as partículas subatômicas (MERCHANT, 1983).

O pensamento orgânico mostra que tudo é conectado a tudo e todas as partes dependem de outra parte e são mutuamente afetadas juntamente com o

Juliana Freitas de Cerqueira Guedes e Ihering Guedes Alcoforado 
todo. Na natureza, nada toma lugar isoladamente, pois quando as pessoas cortam as florestas estão afetando os reservatórios de água cuja vida delas depende. Desta forma, as catástrofes naturais podem ser interpretadas como uma revanche da natureza contra a ação humana (MERCHANT, 1983).

Merchant (1989) compreende a sociedade préindustrial como vinculada à ordem orgânica, ressaltando sua ligação com o gênero feminino. Neste período, os recursos naturais passaram a ser vistos como commodities e o meio ambiente como espaço privado, por meio do que se insere o uso do valor econômico nas comunidades locais. No entanto, mesmo com a ampliação do comércio mercantil e a multiplicação da população, a natureza ainda era vista como uma vice-regente de Deus, virgem, mãe. Os espaços de produção eram femininos e a reprodução social era da família agrícola, em que o agricultor era 'parteiro' da natureza e a esposa 'parteira' dos seres humanos (MERCHANT, 1989).

Já a sociedade industrial é apoiada numa ordem mecânica, cuja relação do homem com a natureza nãohumana é caracterizada pela apropriação do espaço com um sentimento de posse e dominação, em que o ser humano não se sente mais parte da natureza e sim acima da mesma. Esta dominação é ressaltada através do desenvolvimento técnico-científico e da utilização dos recursos naturais com o intuito de auferir lucros e manifesta uma vinculação do pensamento mecânico desta sociedade com o gênero masculino. Desta forma, a representação da natureza passou a ser de uma fêmea passiva, professora de leis mecânicas, de máquina que expressa o domínio masculino (MERCHANT, 1989).

O desenvolvimento científico deste período pode ser expresso na vida e obra do filósofo Bacon que abarcou o período cuja ciência (filosofia natural), tecnologia (mecânica) e o capitalismo mercantil se uniram com a religião para tornar possível uma nova forma de conhecimento (um 'conhecimento avançado') a serviço da humanidade. $\mathrm{O}$ conhecimento científico, para Bacon, tem por finalidade servir o homem e darlhe poder sobre a natureza. É também algo prático, pois saber é poder. O conhecimento, o saber, é apenas um meio vigoroso e seguro de conquistar poder sobre a natureza (MERCHANT, 2008).

Temporalmente, Merchant (1989) aponta dois tipos existentes de Revoluções Ecológicas que já ocorreram: a Revolução Ecológica Colonial, apreendida numa ordem orgânica e a Revolução Ecológica Capitalista, ancorada numa ordem mecânica e aponta a necessidade de uma terceira Revolução Ecológica: a Revolução Ecológica Global, apoiada no ecodesenvolvimento e no ecofeminismo.

Nas sociedades primitivas, a natureza era vista como próprio ativo, os animais e plantas eram subjugados de acordo com as necessidades humanas e a produção do homem baseava-se na caça, na coleta e na pesca num espaço comum de escala local. Neste tipo de sociedade, havia um equilíbrio de populações, a forma de consciência predominante era a mimética, uma consciência visual e o símbolo da natureza que predominava era o animismo, ou seja, a crença de que as forças da natureza possuíam alma. Ambas as Revoluções Ecológicas (Colonial e Capitalista) alteraram a ecologia, a sociedade e a consciência humana e novas estruturas materiais e tecnológicas foram impostas à natureza, transformando as relações do homem com a natureza (MERCHANT, 1989).

A consciência individual e de grupo é formada tanto pelo desenvolvimento quanto pela cultura e, em diferentes tempos históricos, a consciência da sociedade é dominada por características particulares e socialmente construída. Desta forma, a mudança na consciência imposta pela elite dominante caracterizou a Revolução Ecológica Colonial (MERCHANT, 1989) e uma expressão no Brasil da Revolução Ecológica Colonial foi a plantation colonial.

A plantation colonial ou a grande lavoura era constituída pela grande propriedade, pela monocultura e pela produção exclusiva para o exterior, ou seja, produção de commodities. Prado Júnior (2000) observa que o fator que contribuiu para a atividade agrícola na colônia foi a ampliação dos mercados para os seus produtos, ampliação esta, que ocorreu devido ao aumento da população europeia durante o séc. XVIII e ao incremento das atividades econômicas e comerciais em todo o mundo, caracterizando a era da Revolução Industrial.

O desenvolvimento da agricultura neste período, como observa Prado Júnior (2000), é muito mais quantitativo do que qualitativo, com pouco aperfeiçoamento técnico, e disso advém a sua curta duração e predação. Já a Revolução Ecológica Capitalista, se caracteriza por um desenvolvimento agrícola muito mais qualitativo do que quantitativo, mas igualmente predador.

Segundo Paiva Júnior (2000), para a instalação de novas culturas, nada de novo se realizava que o processo da 'queimada', copiada dos indígenas. Já para o problema do esgotamento do solo, outra solução não se descobrira ainda que o abandono puro e simples do local por anos e anos consecutivos, com prazos cada vez mais espaçados que o empobrecimento gradual do solo ia alargando até se tornar definitivo.

O caráter da economia brasileira da época com o sistema de monocultura e de grande propriedade, como observa Prado Júnior (2000), faz convergir para um único fim, com o objetivo de um máximo e

Juliana Freitas de Cerqueira Guedes e Ihering Guedes Alcoforado 
momentâneo proveito, ou seja, uma agricultura extrativa. Paiva Júnior (2000) conclui que a separação entre a agricultura e a pecuária brasileira na época também foi prejudicial para o trato do solo, privando-o do estrume dos animais, único elemento fertilizante de que poderia dispor.

$\mathrm{Na}$ Revolução Ecológica Capitalista, de consciência mecânica, predominante nas sociedades industriais, o homem não se sente como parte da natureza, conectada a ela e, sim acima da mesma, podendo utilizar os recursos naturais da forma que lhes for mais conveniente para auferir lucros. Este tipo de pensamento foi predominante para o desenvolvimento do capitalismo comercial e utilizado como uma justificativa de poder e dominação do homem acima da natureza. Na maioria das vezes, este tipo de atitude acarreta consequências desastrosas para a humanidade na forma de poluição e degradação dos recursos, não se excluindo os desastres (MERCHANT, 1989). O discurso mecanicista capitalista separa a natureza do ser humano para poder explorar e uma manifestação da Revolução Ecológica Capitalista é a agricultura intensiva e extensiva.

Agricultura estas que significou de um lado, a implementação de inovações tecnológicas no sentido de melhorar o desempenho da produtividade na agricultura e de outro, a inserção crescente da agricultura ao complexo agroindustrial através da integração aos setores industriais produtores de insumos e pela vinculação ao mercado transformador da produção agrícola. Em relação às inovações tecnológicas, os exemplos mais frequentes são: desenvolvimento da mecanização e da irrigação, sementes geneticamente modificadas, utilização de defensivos agrícolas (TEIXEIRA E LAGES, 1996).

Bové e Dufour (2001) chamam atenção que a modernização da agricultura é inspirada no modelo industrial com especialização e concentração de propriedades, criação de cadeias de produção e também observam que a atividade agrícola, em termos globais, ocupa metade do território, e, no entanto, é exercida por um décimo das pessoas empregadas há cinquenta anos. A especialização e a uniformização das técnicas fizeram desaparecer os sistemas de produção local associando cultivo e criação, que encontravam o equilíbrio de acordo com a adaptação ao clima e ao solo da região (BOVÉ e DUFOUR, 2001).

O estágio supremo de especialização do grande cultivo é a monocultura. A lavoura do milho, por exemplo, é muito exigente em adubos, herbicidas, pesticidas e o seu caráter monocultor, agrava as coisas em todos os domínios. Há também a especialização entre os animais, em que raças rústicas desaparecem em proveito de raças especializadas que são selecionadas geneticamente. A seleção dos animais se preocupa com dois objetivos: aumento dos rendimentos físicos e comodidade de manipulação e de criação do animal pelo criador (BOVÉ e DUFOUR, 2001).

Quanto aos transgênicos, há uma intervenção sobre o genoma na planta e o princípio é o de fixar no cromossomo da mesma, por meio de manipulação direta, um gene estranho à planta, mas que tenha a propriedade que se deseja. No final, essas sementes são patenteadas e ocorre a possibilidade das empresas fabricantes das sementes processarem na justiça qualquer agricultor que semeie novamente transgênicos com grãos separados de sua colheita precedente. Desta forma, são plantas cuja 'programação' natural da espécie foi trocada (BOVÉ e DUFOUR, 2001).

Além disso, as empresas agroquímicas fizeram que os transgênicos fossem classificados como produtos fitossanitários, com a finalidade de impedir que sua imagem apareça como insuportável ao consumidor e de evitar mais um entrave administrativo à sua inserção no mercado. Em resumo, as causas ligadas ao modelo de modernização da agricultura são: padronização da produção em massa, divisão e a segmentação do trabalho (BOVÉ e DUFOUR, 2001).

Entretanto, a emergência de políticas verdes pelo mundo inteiro é, em parte, a resposta para as falhas que reproduzem a sociedade capitalista para regular a poluição e há a possibilidade de que uma Revolução Ecológica Global possa estar ocorrendo, pois as crises ecológicas globais que transcendem as fronteiras nacionais podem alavancar a transição para um mundo sustentável. Esta transição deverá conter mudanças na produção e na reprodução, enfatizando o ecodesenvolvimento e o ecofeminismo nos países desenvolvidos e em desenvolvimento. As formas coloniais e capitalistas de exploração da natureza devem dar lugar para as prioridades de cumprimento de qualidade de vida, sendo necessários esforços globais para conservar energia e recursos naturais, reciclar os recursos não-renováveis e adotar tecnologias apropriadas para o meio ambiente (MERCHANT, 1989 e 1992).

O pensamento ecológico oferece a possibilidade de um novo relacionamento entre o homem e a natureza não-humana que poderia conduzir para a sustentabilidade da biosfera no futuro. As hipóteses do paradigma ecológico contrastam com o mecanicista restando um conjunto de diferentes proposições sobre a natureza: (1) tudo é conectado a tudo em uma teia integrada; (2) o todo é maior que o total das partes; (3) a natureza não-humana é ativa, dinâmica e reage a ação humana; (4) pessoas e natureza são unificadas no 
todo (MERCHANT, 1989).

Já o pensamento ecofeminista emergiu nos anos 1970 com um aumento de consciência da conexão entre as mulheres e a natureza, o termo surgiu como um convite às mulheres a liderar uma Revolução Ecológica para salvar o planeta. Tal Revolução, que pode fazer parte da Revolução Ecológica Global, implica novas relações de gênero entre homens e mulheres e entre os seres humanos e a natureza. Muitas mulheres ativistas argumentam que homens têm concebido e produzido tecnologias que negligenciam os efeitos da radiação nuclear, pesticidas, resíduos perigosos e produtos químicos domésticos sobre os órgãos reprodutivos das mulheres e sobre o ecossistema (MERCHANT, 1992).

Para o modelo ecológico e ecofeminista substituir o mecânico como um novo paradigma para tomar decisões, requer uma revolução global, social e econômica. Sendo que as relações capitalistas de produção e as relações patriarcais de reprodução que sustentam a consciência mecânica têm que dar lugar a novas formas socioeconômicas, novas relações de gênero e uma ética ecológica global, pois as crises ecológicas globais que transcendem as fronteiras nacionais poderiam alavancar a transição para um mundo sustentável (MERCHANT, 1989).

\section{Revolução Ecológica Capitalista}

A nova filosofia mecânica do meio do século XVII conseguiu a reunificação do cosmo e da sociedade em termos de uma nova metáfora, a máquina. No mundo mecânico, a ordem foi redefinida para dentro de uma determinação racional do sistema das leis e sua dimensão espacial foi universalizada. A ordem e o poder juntos passaram a constituir um controle racional acima da natureza e da sociedade. A máquina permeou e reconstruiu a consciência humana de uma forma tão intensa que hoje nós raramente questionamos sua validade (MERCHANT, 1983).

A mecanização do mundo como um esquema conceitual teve fundamentação, primeiro, na institucionalização da tecnologia da máquina como um ingrediente integral na evolução dos modelos econômicos capitalistas iniciantes. As máquinas enfatizaram simbolicamente na imaginação humana suas capacidades de poder e ordem, o que acabou de certa forma, ordenando a vida do homem. O pensamento mecanicista legitimou a manipulação da natureza, pois é baseado em valores com pretensões de universalidade que são totalmente compatíveis com as direções tomadas pelo capitalismo comercial (MERCHANT, 1983).
$\mathrm{Na}$ Revolução Ecológica Capitalista, as fábricas localizadas em certos países importam recursos naturais de países menos desenvolvidos e exportam produtos finais. Este tipo de transação acarreta poluição do ar, das águas e o esgotamento dos recursos naturais, criando externalidades negativas fora dos cálculos dos lucros das empresas, mas cuja relação de causalidade ação produtiva versus externalidade negativa é perfeitamente estabelecida. A ascensão de uma consciência analítica e quantitativa, para dar conta destas relações de causalidade, foi o traço da Revolução Ecológica Capitalista (MERCHANT, 1989).

Outro aspecto neste processo foi ressaltado por Faucheux e Noël (1995), segundo os quais, o advento da Revolução Industrial foi um grande marco da mudança das relações entre o homem e a natureza, em que as energias ditas 'frias' (hidráulica) são substituídas pelas formas de energias 'quentes' (máquinas térmicas), tendo como grande consequência a substituição da utilização das energias renováveis pelas energias fósseis. A Revolução Ecológica Capitalista pode acarretar impactos ambientas com diferentes espacialidades e temporalidades: locais e reversíveis e globais e irreversíveis.

Um exemplo de impacto ambiental local e reversível pode ser vinculado à poluição e degradação ambiental de pequena intensidade, e de impacto ambiental global e irreversível pode ser associado ao efeito estufa. Os impactos planetários e irreversíveis podem ocorrer tanto na esfera da poluição, da degradação, como dos desastres, que muitas vezes são irreversíveis. Ressaltando que os desastres podem ser intensificados quando interagem com a vulnerabilidade específica de cada comunidade que pode ser física, social, econômica, relacionada ao gênero e ao meio ambiente.

A Revolução Ecológica Capitalista tenta inserir preocupações ambientais no seu interior, mas com a estrita finalidade de ter uma boa visibilidade social e, com isto, preservar o status quo. A Revolução Ecológica Capitalista de Merchant (1989) está inserida no que Dryzec (1997) chama de discurso ambiental. Segundo Dryzec (1997), o discurso ambiental tem início na sociedade industrial e posiciona-o no contexto do discurso dominante da sociedade industrial, que pode ser chamado de industrialismo.

A Revolução Ecológica Capitalista está inserida nos discursos da Resolução de Problemas Ambientais e da Sustentabilidade citados por Dryzec (1997). O discurso da Resolução de Problemas Ambientais mantém o status quo político-econômico capitalista. No entanto, admite que seja preciso ajustes para lidar com os problemas ambientais, especialmente através 
de políticas públicas. Estes ajustes podem assumir a forma pragmática de capacidade de resolução de problemas através de governos liberais democráticos e também através dos mercados, colocando preço sobre os danos e benefícios ambientais, ou através da institucionalização da preocupação ambiental (DRYZEC, 1997).

Já o discurso da Sustentabilidade é definido por tentativas de dissolver os conflitos entre valores ambientais e econômicos que energizam os discursos dos 'limites de crescimento'. Os conceitos de crescimento e desenvolvimento são redefinidos de forma a tornar obsoletas as projeções simples dos discursos limites. Ainda não há consenso sobre o significado exato de sustentabilidade, mas a sustentabilidade é o eixo em torno do qual ocorre a discussão e os limites de crescimento estão longe de serem vistos. O crescimento econômico e a proteção ambiental são vistos como essencialmente complementares (DRYZEC, 1997).

Devido à exploração da natureza pelo homem potencializado pela técnica e consolidado pela Revolução Ecológica Capitalista, Merchant (1989) aponta a necessidade de uma Revolução Ecológica Global durante o século XXI. O pensamento ecológico e ecofeminista oferecem a possibilidade de um novo relacionamento entre o homem e a natureza, que poderia conduzir para a sustentabilidade da biosfera no futuro (MERCHANT, 1989).

\section{Revolução Ecológica Global}

O desenvolvimento ecológico e econômico pode pavimentar o caminho para a transição demográfica que tem abaixado as taxas de reprodução em países desenvolvidos. Mudanças na produção podem auxiliar mudanças na reprodução e ambas podem aliviar a pressão humana no ecossistema global. A Revolução Ecológica Global poderá reconstruir as relações de gênero entre mulheres e homens e entre humanos e a natureza, pois a dominação das mulheres e da natureza é inerente a economia de mercado (MERCHANT, 1989).

A ecologia pode oferecer uma nova ética para as relações entre o homem e a natureza. Pois, se o pensamento mecânico consiste numa ética de 'direitos naturais' em que o homem utiliza a natureza para maximizar o seu próprio interesse, o que pode ser considerada na terminologia filosófica corrente como uma 'ética antropocêntrica' ou 'ética da convicção', a ética ecológica, é baseada numa rede de obrigações mútuas e em valores baseados preferivelmente no ecossistema do que nos interesses humanos, ou seja, é uma 'ética ecocêntrica' (MERCHANT, 1989).

Nesta busca por uma ética ecocêntrica, muitas feministas culturais celebram uma era da pré-história quando a natureza era simbolizada por figuras de fêmeas grávidas, árvores, borboletas e serpentes e cujas mulheres eram tidas em alta estima como portadoras da vida. Lembram que a emergência da cultura patriarcal, contudo, destronou a deusa-mãe e a substituiu por deuses masculinos, a quem as divindades femininas tornaram-se subservientes. O ecofeminismo cultural é uma resposta à percepção de que as mulheres e a natureza têm sido mutuamente associadas e desvalorizadas na cultura ocidental. A saída para este dilema é elevar e liberar as mulheres e a natureza através de ações políticas diretas (MERCHANT, 1992).

Com este propósito revisitam a revolução científica do século XVII para chamar atenção que ela promoveu a degradação da natureza pela substituição do organicismo da Renascença e alimentou a terra com a metáfora da máquina a ser controlada e reparada por forças externas. A ontologia e epistemologia do mecanicismo cientificista são vistos pelas feministas culturais como profundamente masculinizada e de exploração da natureza historicamente representada pelo sexo feminino. O espaço é dominado pelo desenvolvimento-masculino com controle da tecnologia, ciência e indústria (MERCHANT, 1992).

Muitos ativismos ecológicos populares entre as mulheres, embora talvez não explicitamente ecofeminista, baseiam-se implicitamente na motivação da ligação entre a biologia reprodutiva das mulheres (natureza) e a tecnologia masculina projetada (cultura). Elas protestam contra a radioatividade do lixo nuclear, usinas e bombas como uma causa potencial de defeitos congênitos, câncer e à eliminação da vida na Terra. Elas expõem sítios de resíduos perigosos perto de escolas, habitações e que permeiam o solo e água potável, contribuindo para abortos espontâneos, defeitos de nascimento e leucemia (MERCHANT, 1992).

A perspectiva socialista ecofeminista, oferece um ponto de vista para analisar as transformações sociais e ecológicas, bem como sugerir ações sociais que conduzam à sustentabilidade da vida e uma sociedade justa. A transição para um ambiente global sustentável e uma economia humana equitativa que atenda as necessidades das pessoas seria baseada em dois relacionamentos dialéticos, produção e ecologia; produção e reprodução. Nas teorias existentes do desenvolvimento capitalista, reprodução e ecologia são subordinadas à produção. A transição para uma ecologia socialista reverteria às prioridades do capitalismo, tornando a produção subordinada à

Juliana Freitas de Cerqueira Guedes e Ihering Guedes Alcoforado 
reprodução e ecologia (MERCHANT, 1992).

Sendo assim, a ecologia e o ecofeminismo são tratados como uma nova visão de mundo que poderia resolver os problemas de desenvolvimento enraizados no modo industrial-mecanicista de representar a natureza. A Revolução Ecológica Global de Merchant (1989) está inserida nos discursos do Survivalismo e do Radicalismo Verde citados por Dryzec (1997).

O discurso do Suvivalismo tem a ideia básica que o crescimento econômico e populacional contínuo acabará por atingir limites estabelecidos pelo choque entre os recursos naturais e a capacidade de apoio dos ecossistemas à atividade agrícola e industrial humana. É um discurso que tem como base o limite ao crescimento econômico, atacando, assim, um crescimento econômico perpétuo (DRYZEC, 1997).

O discurso do Radicalismo Verde rejeita a estrutura básica da sociedade industrial e o modo como o meio ambiente é contextualizado por esta sociedade em favor de uma variedade de interpretações alternativas dos seres humanos, sua sociedade e seu lugar no mundo (DRYZEC, 1997).

O que Merchant (1989) desconsidera é que estamos na verdade nos deslocando da dimensão ergódica para a não-ergódica do meio ambiente. Em um ambiente ergódico, a estabilidade é subjacente a sua estrutura, ou seja, é um ambiente imutável que não está em constante transformação, em que as leis naturais são causais, o que permite não só a previsão dos efeitos, mas também sua reversão.

No entanto, o mundo em que vivemos é nãoergódico, dinâmico e em constante transformação, não somente em termos de mudanças físicas, mas também na estrutura social e na conduta da ação humana. Entretanto, todas as teorias que temos na economia operam com a dimensão ergódica (NORTH, 1999). Podemos concluir que o ambiente ergódico se relaciona com o pensamento mecanicista $\mathrm{e} a$ Revolução Ecológica Capitalista, assim como a dimensão não-ergódica tem ligação com a Revolução Ecológica Global e o pensamento ecológico e ecofeminista.

Desta forma, os impactos ambientais locais e reversíveis são possíveis de serem equacionados por um framework fundado numa representação mecanicista da natureza e expresso por meio do paradigma da 'política da convivência'. O universo da convivência, segundo Abélès (2008), corresponde a uma tradição política vigente fundamentalmente centrada na harmonia sincrônica entre seres humanos que se movem dentro de um universo tranquilizador ou que, pelo menos, orientam suas ações levando em consideração este horizonte, mesmo quando em conflito incessante de destruição.
Esta abordagem não dá conta dos impactos ambientais imprevisíveis, planetários e irreversíveis, os quais requerem que respondamos não apenas por nossas intenções, mas também pelas consequências de nossos atos, tanto os intencionais quanto os não intencionais. Ou seja, segundo Abélès (2008), torna-se necessário uma 'política da sobrevivência' enquanto fundamento de uma política ambiental para as sociedades humanas neste século XXI, marcado pelo uso crescente de novas tecnologias geradoras de impactos globais e irreversíveis.

\section{Conclusão}

As decisões acerca da escolha da política ambiental só fazem sentido enquanto se admite que a relação entre atividade produtiva e seu efeito tem um tempo e um espaço, a partir do qual enquadramos o meio ambiente, o qual pode se manifestar predominantemente na sua dimensão ergódica ou na não-ergódica da natureza. No tempo presente, quando os efeitos da ação humana se manifestam na dimensão não-ergódica numa escala temporal e/ou espacial planetária, devemos recorrer a novos tipos de políticas ambientais fundadas numa representação orgânica da natureza como não-ergódica, situação que segundo North (1999), não é a exceção, mas a regra no caso.

Devido a irreversibilidade das ações humanas que ampliam a dimensão não-ergódica, é necessária uma ação responsável, sendo que a ética tem que dar instruções a cada vez mais necessária autovigilância do desmesurado poder humano com o planeta e o futuro pondo a própria sobrevivência da espécie humana em perigo, torna-se imperativo agirmos de forma responsável. Esta instrução é sintetizada na versão de Jonas (1995, p.40) do imperativo categórico kantiano: "Ajas de tal modo que os efeitos de tua ação sejam compatíveis com a permanência de uma vida humana autêntica na terra" ou expresso de forma negativa "Aja de tal modo que os efeitos de tua ação não sejam destrutivos para a futura possibilidade dessa vida".

$\mathrm{Na}$ ética da responsabilidade inspirada em Jonas (1995) é necessário refletir nas ameaças para nos assegurarmos das normas. O primeiro dever é visualizar as consequências da sociedade industrial e tecnológica, pois numa ética do futuro temos de antecipar as condições desastrosas. $\mathrm{O}$ segundo dever observado é que o mal distante imaginado não suscita o mesmo receio que o mal presente. Sendo assim, é necessária uma política muito ativa no que diz respeito às crenças e aos valores de cada sociedade relacionada com os desastres.

Os impactos globais e irreversíveis só são possíveis

Juliana Freitas de Cerqueira Guedes e Ihering Guedes Alcoforado 
de serem equacionados através de uma representação orgânica e holística da natureza, que se expressa por meio do paradigma da política da sobrevivência. Desta forma, imaginamos um programa de investigação que busque integrar a ética da responsabilidade de Jonas (1995) no núcleo duro da Revolução Ecológica Global de Merchant (1989), cujos pontos fundamentais são o ecodesenvolvimento e o ecofeminismo, e assim contribuir na construção de um novo framework que nos permita enfrentar os desafios ambientais planetários que caracterizam o tempo presente.

\section{Referências}

ABÉLÈS, Marc. Política de la supervivência. Buenos Aires: Eudeba, 2008.

BOVÉ, José; DUFOUR, François. O mundo não é uma mercadoria: camponeses contra a comida ruim. São Paulo: Editora UNESP, 2001.

DRYZEC, John. The Politics of the Earth. Oxford: Oxford University Press, 1997.

FAUCHEUX, Sylvie; NOËL, Jean - François. Economia dos recursos naturais e do meio ambiente. Lisboa: Instituto Piaget, 1995.

JONAS, Hans. El principio de responsabilidad: ensayo de una ética para la civilización tecnológica. Barcelona: Editorial Herder, 1995.

MERCHANT, Carolyn. The death of nature: women, ecology and the scientific revolution. San Francisco: Harper San Francisco, 1983.

Ecological revolutions: nature, gender and science in New England. Chapel Hill: The University of North Carolina Press, 1989.

Radical Ecology: The Search for a Livable World. New York: Routledge, Chapman \& Hall, 1992.

Secrets of Nature: The Bacon Debates Revisited. Journal of the History of Ideas, v. 69, n. 1, p. 147-162, 2008.

NORTH. Douglass. Dealing with a non-ergodic world: institutional economics, property rigths, and the global environment. Environmental law \& policy forum, v. 10, n.1, p.1 - 12, 1999.

PRADO JÚNIOR, Caio. Formação do Brasil
Contemporâneo. São Paulo: Publifolha, 2000.

TEIXEIRA, Olívio Alberto; LAGES, Vinícius Nobre. Do produtivismo à construção da agricultura sustentável: duas abordagens pertinentes a questão. Cadernos de ciência e tecnologia, v. 13, n. 3, p. 347 368, 1996. 